\title{
Validation of the Short Self-Regulation Questionnaire in a group of Black teachers: The SABPA study
}

\begin{tabular}{|c|c|}
\hline \multicolumn{2}{|c|}{$\begin{array}{l}\text { Authors: } \\
\text { Mariette Vosloo }{ }^{1} \\
\text { Johan Potgieter }^{1} \\
\text { Michael Temane }^{1} \\
\text { Suria Ellis } \\
\text { Tumi Khumalo }\end{array}$} \\
\hline \multicolumn{2}{|c|}{$\begin{array}{l}\text { Affiliations: } \\
{ }^{1} \text { School for Psychosocial } \\
\text { Behavioural Sciences, } \\
\text { North-West University, } \\
\text { Potchefstroom Campus, } \\
\text { South Africa }\end{array}$} \\
\hline $\begin{array}{l}{ }^{2} \text { Statistical Cor } \\
\text { Services, Nort } \\
\text { University, Pot } \\
\text { Campus, Sout }\end{array}$ & $\begin{array}{l}\text { Isultation } \\
\text { h-West } \\
\text { chefstroom } \\
\text { Africa }\end{array}$ \\
\hline \multicolumn{2}{|c|}{$\begin{array}{l}\text { Correspondence to: } \\
\text { Johan Potgieter }\end{array}$} \\
\hline \multicolumn{2}{|c|}{$\begin{array}{l}\text { Email: } \\
\text { johan.potgieter@nwu.ac.za }\end{array}$} \\
\hline \multicolumn{2}{|c|}{$\begin{array}{l}\text { Postal address: } \\
\text { Private Bag X6001, } \\
\text { Potchefstroom 2520, } \\
\text { South Africa }\end{array}$} \\
\hline \multicolumn{2}{|c|}{$\begin{array}{l}\text { Dates: } \\
\text { Received: } 06 \text { June } 2013 \\
\text { Accepted: } 20 \text { Aug. } 2013 \\
\text { Published: } 13 \text { Nov. } 2013\end{array}$} \\
\hline \multicolumn{2}{|c|}{$\begin{array}{l}\text { How to cite this article: } \\
\text { Vosloo, M., Potgieter, } \\
\text { J., Temane, M., Ellis, S., } \\
\text { \& Khumalo, T. (2013). } \\
\text { Validation of the Short Self- } \\
\text { Regulation Questionnaire in } \\
\text { a group of Black teachers: } \\
\text { The SABPA study. SA Journal } \\
\text { of Industrial Psychology/SA } \\
\text { Tydskrif vir Bedryfsielkunde, } \\
\text { 39(1), Art. \#1157, } 10 \text { pages. } \\
\text { http://dx.doi.org/10.4102/ } \\
\text { sajip.v39i1.1157 }\end{array}$} \\
\hline \multicolumn{2}{|c|}{$\begin{array}{l}\text { Copyright: } \\
\text { (C) 2013. The Authors. } \\
\text { Licensee: AOSIS } \\
\text { OpenJournals. This work } \\
\text { is licensed under the } \\
\text { Creative Commons } \\
\text { Attribution License. }\end{array}$} \\
\hline \multicolumn{2}{|l|}{ Read online: } \\
\hline 口ifris & $\begin{array}{l}\text { Scan this QR } \\
\text { code with your } \\
\text { smart phone or } \\
\text { mobile device } \\
\text { to read online. }\end{array}$ \\
\hline
\end{tabular}

Orientation: Recent literature has emphasised the important role that self-regulation plays in the mental health of individuals. The lack of a validated psychometric instrument to accurately measure self-regulation amongst Black South Africans however limits its potential impact within the challenging South African context.

Research purpose: The aim of this study was to investigate the psychometric properties of the Short Self-Regulation Questionnaire (SSRQ) when used in a South African context, specifically focusing on Black South Africans.

Motivation for the study: By commenting on the ability of the SSRQ to accurately capture the construct of self-regulation amongst Black educators, the current article serves to address and alleviate the lacunae in our understanding of self-regulation as a potentially protective factor.

Research design, approach and method: The study was of a quantitative nature, and made use of a cross-sectional design and purposively selected study sample. Participants were urbanised Black teachers $(N=200)$ who completed the SSRQ and other measures of self-regulation and psychological well-being.

Main findings: The reliability of the SSRQ total scale score proved satisfactory. Factor analysis produced five robust sub-constructs that were theoretically interpretable. Significant correlations between the SSRQ and other measures of self-regulation and psychological wellbeing also indicated good criterion-related validity.

Practical/managerial implications: The availability of a reliable and valid instrument for the measurement of self-regulation in the South African context will enable both researchers and practitioners to better understand and utilise self-regulation in the enhancement of individual well-being.

Contribution/value-add: The SSRQ's ability to accurately measure self-regulation will contribute to our understanding of its role as preventive strength in the South African context. Refinement of item content will serve to further strengthen the SSRQ's factor structure, and improve its validity for use within the Black South African population.

\section{Introduction}

More than two decades ago, South Africa was identified by Nations for Mental Health, a project by the World Health Organization (WHO), as one of the most underserved populations in terms of mental health and psychological well-being (Saraceno, 1998). Although much time has passed, the South African context still poses significant challenges to the health and well-being of its citizens due to factors like pervasive socio-economic disparities (Møller, 2007), the fragmented and under-resourced state of the public mental health service (Lund \& Flisher, 2006) and the challenges of coping with the HIV and AIDS pandemic (Ferreira, 2008).

Within this challenging context, the teaching occupation has recently attracted a great deal of attention as a particularly stressful context. Job demands (overload), a lack of personal growth opportunities, lack of control because of limited resources, and numerous reforms that have been introduced within the teaching profession since 1994 are reportedly experienced as overwhelming by teachers (Coetzee, Jansen \& Muller, 2008). Because of the stress associated with their working environment, and the resultant lowered levels of job satisfaction and motivation reported by South African educators (Jackson \& Rothmann, 2005), an increasing number of teachers are leaving the profession (Parker, Martin, Colmar \& Liem, 2012). This has created a need for the exploration of innovative and effective avenues for not only the prevention of mental disorders in the general population (WHO, 2004; 2013), but also the improvement of psychological wellbeing of teachers specifically (Khan, 2012). One such possibility that has shown promise both internationally (Caprara \& Steca, 2006; Siegel, 2007; Skowron, Holmes \& Sabatelli, 2003) and locally (Potgieter \& Botha, 2009) is that of self-regulation. 
Broadly described as the self's capacity for altering its behaviour (Baumeister \& Vohs, 2007), effective selfregulation has been found to encompass the management and control of processes such as thinking, emotion, attention and concentration (Beckmann \& Kellmann, 2004). Directing these processes enables an individual to flexibly adjust their pattern of response to a range of contextual demands (Siegel, 2007), and to maintain autonomous and adaptive behaviour even in less-than-desirable circumstances (Sokol \& Müller, 2007). This goal-oriented process allows people to effectively regulate their actions in moving towards need fulfillment or a desired aim (Carey, Neal \& Collins, 2004). Effective selfregulation has been linked to a variety of positive outcomes, including the maintenance of mental health and psychological well-being, increased performance at school and work, and positive relationships (Aspinwall, 2004; Forgas, Baumeister \& Tice, 2009; Ibaňez, Ruipérez, Moya, Marqués \& Ortet, 2005; Skowron et al., 2003).

Within the taxing working environment faced by South African educators, the potential for effective self-regulation to protect an individual against the negative outcomes of stress (Baumann, Kaschel \& Kuhl, 2005) seems especially relevant. In addition to affecting the capacity to cope with stress, self-regulation has been found to influence the likelihood of experiencing such negative events (Gramzow, Sedikides, Panter \& Insko, 2000) because it enables individuals to anticipate and avoid or otherwise minimise the adverse impact of stressful events (Aspinwall \& Taylor, 1997). In acting both as a buffer against the detrimental effects of stress and as a preventative measure against its occurrence, self-regulation has been found to contribute significantly to the maintenance of psychological well-being in various contexts and populations (Allard, 2007; Caprara \& Steca, 2006; Skowron et al., 2003).

In an attempt to measure this construct with its apparent importance for the maintenance of psychological wellbeing, Brown, Miller and Lawendowski (1999) formulated the 63-item self-report Self-Regulation Questionnaire (SRQ) from seven rationally derived dimensions conceptualised as necessary for effective self-regulation. These dimensions were: (1) attention to informational input, (2) self-evaluation by comparing oneself to a standard, (3) willingness to consider change, (4) engagement in search processes for alternatives to meet the change goal, (5) devising a clear plan, (6) implementing and maintaining the plan and (7) subsequent evaluation of the plan. During further psychometric analysis of the SRQ, Carey et al. (2004) found a single-factor solution for the SRQ that consisted of 31 items. These items were combined to create a shortened version of the SRQ (SSRQ) that was highly correlated $(r=0.96)$ with the original SRQ.

Although an investigation by Potgieter and Botha (2009) of the SSRQ's psychometric properties in a South African student sample yielded promising results, this sample included a limited number of participants of African descent, and the SSRQ's validity within more collectivistic Black groups therefore remain untested.
In spite of the large body of evidence linking self-regulation to both the maintenance of psychological well-being and the prevention of the development of disorders (Siegel, 2007; Skowron et al., 2003; Sokol \& Müller, 2007), a number of researchers have stressed the fact that cultural and contextual factors have a direct impact on both the construction and experience of psychological well-being (Temane \& Wissing, 2008; Wissing \& Temane, 2008; Wissing, Wissing, Du Toit \& Temane, 2006). It can therefore not be assumed that the measurement of self-regulation, and its role in maintenance of well-being within a collectivistic African context (Wissing \& Temane, 2008), will be identical to what has been found in Westerns contexts or cultural settings, which are predominantly individualistic. An important initial step towards discovering the role of self-regulation in the ability of Black African teachers to cope would be to accurately measure this construct in order to allow for cross cultural comparison. The aim of this study was therefore to explore the psychometric properties of the SSRQ within a group of Black African teachers.

\section{Research method Research design}

This study formed part of the longitudinal and transdisciplinary Sympathetic Activity and Ambulatory Blood Pressure in Africans (SABPA) project, which ran from January 2008 to May 2012 (Mashele, Van Rooyen, Malan \& Potgieter, 2010), and had the overarching purpose to investigate the markers of bio-psycho-social health in urbanised teachers. Quantitative data collected from January to May of 2008 as part of the baseline phase of the SABPA project was used for this validation study.

\section{Participants}

Data were obtained from a total of 200 urbanised Black African teachers, 101 men and 99 women, aged between 21 and 62 years. Participants were recruited from one of the four education districts in the Dr Kenneth Kaunda Education district of North West province (South Africa) during 2007. In order to be eligible for participation, participants had to comply with the following criteria for purposes of the physiological component of the overarching SABPA project: not pregnant or lactating, not donating blood on a regular basis, not using acute or chronic medication for hypertension, diabetes, arthritis, tuberculosis, coagulation factors, inflammation, epilepsy or mental disorders (antidepressants), and not been vaccinated in the previous three months (Mashele et al., 2010).

\section{Measures}

In addition to the SSRQ, data from a number of other questionnaires that formed part of the psychosocial battery of the SABPA project were used for the purposes of this study. This included another measure of self-regulation, as well as various indices of psychological well-being in order to shed light on the SSRQ's concurrent validity. All measures were presented in English, as participants were all competent in English as a second language. 
The Short Self-Regulation Questionnaire: The 31-item SSRQ is a short version of the original SSRQ (Brown, Miller \& Lawendowski, 1999). Whilst the original full-length scale measured self-regulation as a process comprising seven steps (i.e. receiving relevant information, evaluating the information and comparing it to norms, triggering change, searching for options, formulating a plan, implementing the plan, and finally assessing the plan's effectiveness) (Brown et al., 1999), Carey et al. (2004) proposed a shorter 31-item version. The scale contains statements regarding the testtakers' self-regulation (e.g. 'I set goals for myself and keep track of my progress'), and utilises a five-point Likert-type response format with response possibilities ranging from 1 (strongly disagree) to 5 (strongly agree). This scale yielded a single factor solution in a sample of American undergraduate students, with a Cronbach's alpha of .92 for the total scale score (Carey et al., 2004). Subsequent analysis of the SSRQ in a group of 237 students in an introductory psychology course (Neal \& Carey, 2005) in the United States revealed two distinct factors (i.e. impulse control and goal setting) with acceptable reliability. Differential patterns of relationships between these factors and measures of self-control and alcohol use also produced evidence for its validity.

The Self-Regulation Scale: The Self-Regulation Scale (SRS) contains seven items measuring participants' self-regulation, and specifically their attention control in the process of goal pursuit (e.g. 'If an activity requires a problem-oriented attitude, I can control my feelings'.). It utilises a four-point Likert-type response format with response options ranging from 'Not at all true' to 'Exactly true'. As mentioned previously, the lack of measures of self-regulation that have been validated in the South African context served as primary motivation for the current study. The SRS yielded a Cronbach's alpha of .76 in a German sample (Schwarzer, Diehl \& Schmitz, 1999). In the current study, the SRS yielded a Cronbach's alpha of .71. Although there are no South African data available for the SRS, it was included in the current study in order to shed some light on the SSRQ's criterion-related validity in the current context.

Because of the proven association between effective selfregulation and psychological well-being, two measures of individual psychological well-being were included to further assist with the establishment of the SSRQ's concurrent validity.

The Mental Health Continuum - Short Form: The Mental Health Continuum - Short Form (MHC-SF) contains 14 items, assessing the frequency of individual's self-reported experience of positive signs of mental health in three distinct areas: emotional well-being (EWB) (items 1-3), social wellbeing (SWB) (items 4-8) and psychological well-being (PWB) (items 9-14) (see Keyes, 2005). The scale uses a sixpoint Likert-type response format ranging from 0 (never) to 5 (every day). A Cronbach's alpha of .74 was yielded for the total MHC-SF scale in a random sample of Setswanaspeaking adults in the North West province of South Africa. The scale was also found to be a valid measure of mental health in the South African context (Keyes et al., 2008). The Cronbach's alpha ranged between .80 and .84 for the different subscales of the MHC-SF in the current sample.

The General Health Questionnaire: The 28-item version of the General Health Questionnaire (GHQ) measures common symptoms that are indicative of the various syndromes of mental disorder (Goldberg \& Hillier, 1979). It utilises a four-point Likert-type response format, giving respondents an opportunity to indicate the extent to which they have experienced four clusters of symptoms, including somatic symptoms (SS), anxiety and insomnia (AI), social dysfunction (SD) and severe depression (DS) in the weeks prior to testing. This study utilised the 'GHQ scoring method' (Goldberg \& Hillier, 1979), which means that responses were scored 0-0$1-1$, producing a potential minimum scale score of 0 and a maximum of 28. Keyes et al. (2008) reported Cronbach's alpha reliability indices of .74 (SS), .74 (AS), .55 (SD), .75 (DS) and .89 (total scale) in a random sample of Setswana-speaking adults in the North West province of South Africa. This scale was also found to show construct validity in the South African context (Wissing \& Van Eeden, 2002). Cronbach's alpha values ranged between .77 and .85 for the GHQ total and subscale scores in the current sample.

\section{Procedure}

This study is a crosscutter between the SABPA and FORT3 (Fortology: The prevalence of levels of psychosocial health: dynamics and relationships with biomarkers of (ill)health in South African social contexts) projects, conducted within the Africa Unit for Transdisciplinary Health Research (AUTHeR). The SABPA project was conducted by various subject groups within the Faculty of Health Sciences of North-West University (NWU). The overarching purpose of this multidisciplinary project was to investigate the markers of bio-psycho-social health in urbanised teachers from the Potchefstroom area of North West province at baseline (2008-2009) and three-year follow-up (2011-2012). The psychological aspect of the data collection process involved the completion of a set of questionnaires, whilst several physiological measurements were taken as part of the biological aspect of the research.

For the purposes of this validation study, the baseline data obtained from January to May of 2008 are used. Data collection took place at the Metabolic Unit (MU) at NWU, in a comfortable, relaxing environment. A maximum of four participants per day were transported to the MU after work. After being welcomed and oriented to their settings, participants completed the psychosocial battery in two sessions on either side of their dinner. Participants spent the night at the MU, and were allowed to return to work the next morning after various physiological measurements were taken (Mashele et al., 2010). As the collection of physiological data only followed the next morning, it is unlikely that this aspect had any influence on psychological data collected the previous evening. Feedback on the results obtained via psychological measures was later given in the form of an 
information session, which was followed by a workshop on stress management.

\section{Data analysis}

According to Paunonen and Ashton (1998), the cross-cultural applicability and construct validity of a psychological test can be determined by assessing psychometric properties such as reliability, criterion validity and internal structure. If these properties approximate those of the original culture, the scale is said to be applicable and valid in the new culture. If the properties are different, however, these authors suggest that results need to be considered according to the various ways in which such differences may have come about.

Following the guidelines proposed by Paunonen and Ashton (1998), the SPSS program was used to explore five psychometric properties considered essential in determining the cross-cultural applicability of a scale. These included scale means, variances, reliability, criterion-related validity and factor structure. Firstly, means, standard deviations and reliability coefficients such as Cronbach's alpha and itemtotal correlations were computed as indicators of internal consistency and homogeneity of the SSRQ. Secondly, the factor structure of the SSRQ was examined by conducting an exploratory factor analysis (i.e. a principal components analysis with oblique rotation) of the data. Relevant indices indicating the factorability of data such as the Kaiser-MeyerOlkin (KMO) measure of sampling adequacy and Bartlett's test of sphericity are reported. Thirdly, criterion-related validity was determined by correlating the SSRQ with the SRS (Schwarzer et al., 1999) as well as two measures of psychological well-being which included the MHC (Keyes, 2005) and the GHQ (Goldberg \& Hillier, 1979).

\section{Ethical considerations}

Ethical permission for both the SABPA and FORT3 projects was obtained from the ethics committee of NorthWest University, South Africa (ethical clearance numbers NWU-00036-07-S6 and NWU-00002-07-A2 respectively). Participants' informed consent was obtained prior to data collection. No risks or discomforts were foreseen and anonymity was maintained by means of using participant numbers. The fieldworkers involved in data collection were all trained in psychological measurement, and worked under supervision of registered psychologists. Participants had the choice to receive feedback in a group format, and those interested were invited to attend a group feedback session and stress-reduction workshop hosted by the researchers after data analysis was completed.

\section{Results \\ Descriptive statistics}

Descriptive statistics and reliability indices for the individual SSRQ items are reported in Table 1. A total of 19 data sets had to be removed due to incomplete data, so the eventual number of participants included in the analysis was 181 . With possible scores ranging from a minimum of 1 to a maximum of 5, item means for these items mostly ranged between 3.0 and 4.0. Exceptions include item 22 with a mean of 2.48 and items 18, 21, 23, 27 and 29 with means just above 4.0. Skewness ranged from -1.52 (item 18) to 0.41 (item 22). With the exception of items 9, 18, 19, 23, 27 and 29, most of the items' skewness values were close to zero, indicating that the data was relatively normally distributed. The kurtosis of individual items ranged from -0.97 to a maximum of 4.29 , with items 18, 21, 23, 27 and 29 displaying large deviation from the Gaussian or normal distribution. The possible implications of these results will receive further attention during the discussion of results.

The majority of the items yielded item-total correlations that fell within the desirable range of between 0.15 and 0.55 , as described by Clark and Watson (1995), reflecting positively on the degree of homogeneity of the SSRQ. Items 16, 18, 22 and 28, however, fell outside of these guideline values. With regard to the value of the Cronbach's alpha of the scale if a specific item is deleted, the value of the Cronbach's alpha diminished for all except item 28, indicating that the vast majority of items contributed positively to the total scale's reliability. A Cronbach's alpha of .86 was yielded for the SSRQ total scale score, lending further support to its reliability. According to Nunnally and Bernstein (1994), a Cronbach's alpha of 70 can be regarded as sufficient during the early phases of scale validation. The overall homogeneity and reliability of the SSRQ can therefore be considered satisfactory.

\section{Factor analysis}

Confirmatory factor analysis showed that the single-factor solution proposed by Carey et al. (2004) did not explain a sufficient amount of variance in the current sample. As principal components analysis is the recommended extraction method for psychological data where the correlations are typically large (Howitt \& Cramer, 2008), a principal component exploratory analysis with oblique rotation was subsequently done. This analysis revealed eight factors with an eigenvalue of 1.13 that cumulatively explained 58.35\% of the total variance. The results of the factor analysis are provided in Table 2.

The KMO measure of sampling adequacy was .819 . According to Field (2013), values above .80 reflect that the data contains correlations that are high enough to produce a compact factor structure. The Bartlett's test of sphericity was significant $\left(\chi^{2}=1856.144, n=200, d f=465\right.$ and $p<$ $0.0001)$, supporting the factorability of the data. Of the eight factors that were extracted, two had less than the minimum number of three items per factor as suggested by Costello and Osborne (2005). Although all of the items loaded higher than the minimum criterion of .35 on at least one factor, which generally suggests robust factor structure (Costello \& Osborne, 2005), caution was used in interpreting those factors affected by the presence of a limited number of cross-loading items. Communalities, which serve as an indication of the amount of information retained in each item after factors 
TABLE 1: Descriptive statistics and reliability indices of the Short Self-Regulation Questionnaire items.

\begin{tabular}{|c|c|c|c|c|c|c|c|c|}
\hline \multirow[t]{2}{*}{ Item } & \multirow[t]{2}{*}{$M$} & \multirow[t]{2}{*}{ SD } & \multicolumn{2}{|c|}{$\mathbf{R}$} & \multirow[t]{2}{*}{ Skew } & \multirow{2}{*}{ Kur } & \multirow[t]{2}{*}{ CT } & \multirow[t]{2}{*}{ CA } \\
\hline & & & Minimum & Maximum & & & & \\
\hline SSRQ1 & 3.28 & 1.11 & 1.00 & 5.00 & -0.25 & -0.82 & .43 & .856 \\
\hline SSRQ2 & 3.42 & 1.09 & 1.00 & 5.00 & -0.54 & -0.57 & .40 & .857 \\
\hline SSRQ4 & 3.62 & 1.13 & 1.00 & 5.00 & -0.63 & -0.28 & .40 & .857 \\
\hline SSRQ5 & 3.63 & 0.89 & 1.00 & 5.00 & -0.68 & 0.44 & .38 & .857 \\
\hline SSRQ6 & 3.77 & 0.84 & 1.00 & 5.00 & -1.15 & 1.71 & .34 & .858 \\
\hline SSRQ8 & 3.61 & 1.15 & 1.00 & 5.00 & -0.8 & -0.21 & .45 & .855 \\
\hline SSRQ9 & 3.91 & 0.88 & 1.00 & 5.00 & -1.31 & 2.36 & .41 & .856 \\
\hline SSRQ10 & 3.39 & 0.97 & 1.00 & 5.00 & -0.64 & -0.18 & .46 & .855 \\
\hline SSRQ11 & 3.20 & 1.05 & 1.00 & 5.00 & -0.38 & -0.63 & .34 & .858 \\
\hline SSRQ12 & 3.80 & 0.86 & 1.00 & 5.00 & -0.68 & 0.71 & .21 & .861 \\
\hline SSRQ13 & 3.80 & 0.85 & 1.00 & 5.00 & -0.98 & 1.15 & .56 & .853 \\
\hline SSRQ14 & 3.81 & 0.82 & 1.00 & 5.00 & -0.87 & 1.33 & .47 & .855 \\
\hline SSRQ15 & 3.41 & 0.93 & 1.00 & 5.00 & -0.30 & -0.50 & .35 & .858 \\
\hline SSRQ17 & 3.86 & 1.01 & 1.00 & 5.00 & -0.93 & 0.36 & .54 & .853 \\
\hline SSRQ18 & 4.15 & 0.80 & 1.00 & 5.00 & -1.52 & 3.99 & .10 & .863 \\
\hline SSRQ19 & 3.86 & 0.75 & 1.00 & 5.00 & -1.02 & 2.49 & .50 & .855 \\
\hline SSRQ20 & 3.97 & 0.80 & 1.00 & 5.00 & -0.89 & 1.41 & .50 & .854 \\
\hline SSRQ21 & 4.01 & 0.74 & 2.00 & 5.00 & -0.91 & 1.35 & .38 & .857 \\
\hline SSRQ22 & 2.48 & 0.84 & 1.00 & 5.00 & 0.41 & -0.02 & .08 & .864 \\
\hline SSRQ23 & 4.11 & 0.80 & 1.00 & 5.00 & -1.11 & 2.07 & .40 & .857 \\
\hline SSRQ24 & 3.60 & 0.89 & 1.00 & 5.00 & -0.32 & -0.20 & .34 & .858 \\
\hline SSRQ25 & 3.72 & 1.02 & 1.00 & 5.00 & -0.59 & -0.32 & .52 & .853 \\
\hline SSRQ26 & 3.56 & 1.00 & 1.00 & 5.00 & -0.55 & -0.29 & .56 & .852 \\
\hline SSRQ27 & 4.09 & 0.78 & 1.00 & 5.00 & -1.19 & 2.56 & .42 & .856 \\
\hline SSRQ28 & 3.09 & 1.11 & 1.00 & 5.00 & -0.04 & -0.97 & .05 & .867 \\
\hline SSRQ29 & 4.27 & 0.73 & 1.00 & 5.00 & -1.50 & 4.29 & .25 & .860 \\
\hline SSRQ30 & 3.88 & 0.77 & 1.00 & 5.00 & -0.62 & 0.76 & .33 & .858 \\
\hline SSRQ31 & 3.62 & 1.25 & 1.00 & 5.00 & -0.66 & -0.64 & .34 & .859 \\
\hline
\end{tabular}

M, mean; SD, standard deviation; R, range; Skew, skewness; Kur, kurtosis; CT, correlation with the total; CA, Cronbach's alpha if item deleted; SSRQ, Short Self-Regulation Questionnaire.

TABLE 2: Pattern matrix of exploratory factor analysis using the principal components method of factor extraction, with oblimin rotation.

\begin{tabular}{|c|c|c|c|c|c|c|c|c|c|}
\hline \multirow[t]{2}{*}{ Variable } & \multicolumn{8}{|c|}{ Factor loadings } & \multirow[t]{2}{*}{ Comm } \\
\hline & 1 & 2 & 3 & 4 & 5 & 6 & 7 & 8 & \\
\hline SSRQ17 & .669 & - & - & - & - & - & - & - & .615 \\
\hline SSRQ8 & .646 & - & - & - & - & - & - & - & .569 \\
\hline SSRQ31 & .638 & - & - & & .352 & - & - & - & .583 \\
\hline SSRQ26 & .602 & - & - & - & - & - & - & - & .579 \\
\hline SSRQ25 & .601 & - & - & - & - & - & - & - & .513 \\
\hline SSRQ7 & .569 & - & - & - & - & - & - & - & .618 \\
\hline SSRQ16 & .499 & - & - & - & - & - & - & - & .554 \\
\hline SSRQ29 & - & .716 & - & - & - & - & - & - & .534 \\
\hline SSRQ24 & - & .672 & - & - & - & - & .359 & & .583 \\
\hline SSRQ30 & - & .591 & - & - & - & - & - & - & .479 \\
\hline SSRQ27 & - & .584 & - & - & - & - & - & - & .555 \\
\hline SSRQ19 & - & .497 & - & - & - & - & - & - & .593 \\
\hline SSRQ20 & - & .426 & - & - & - & - & - & - & .589 \\
\hline SSRQ6 & - & - & .806 & - & - & - & - & - & .623 \\
\hline SSRQ14 & - & - & .717 & - & - & - & - & - & .639 \\
\hline SSRQ1 & - & - & - & -.709 & - & - & - & - & .684 \\
\hline SSRQ2 & - & - & - & -.674 & - & - & - & - & .595 \\
\hline SSRQ21 & - & - & - & .414 & - & - & -.382 & & .624 \\
\hline SSRQ10 & - & - & - & -.379 & - & - & - & - & .486 \\
\hline SSRQ11 & - & - & - & -.368 & - & - & - & - & .520 \\
\hline SSRQ22 & - & - & - & - & .700 & - & - & - & .569 \\
\hline SSRQ23 & - & - & - & - & -.551 & - & - & - & .534 \\
\hline SSRQ4 & - & - & - & - & .466 & - & - & .428 & .582 \\
\hline SSRQ28 & - & - & - & - & - & .709 & - & - & .678 \\
\hline SSRQ18 & - & - & - & - & - & -.661 & - & - & .620 \\
\hline SSRQ9 & - & - & - & - & - & - & -.755 & - & .636 \\
\hline SSRQ12 & - & - & - & - & - & - & -.685 & - & .576 \\
\hline SSRQ13 & - & - & .390 & - & - & - & -.517 & - & .661 \\
\hline SSRQ15 & - & - & - & - & - & - & - & .732 & .606 \\
\hline SSRQ3 & - & - & - & .409 & - & - & - & .445 & .552 \\
\hline
\end{tabular}

Comm, communality estimates; SSRQ, Short Self-Regulation Questionnaire.

Values less than 0.35 are not displayed. 
have been extracted (Hair, Anderson, Tatham \& Black, 2005) ranged from .48 to .68. According to Costello and Osborne (2005), low to moderate communalities (ranging from .40 to .70) can be expected in the social sciences. Of the eight factors that were extracted, five readily lent themselves to theoretical interpretation, contained more than three items each, and displayed a Cronbach's coefficient alpha of larger than .6. These factors were retained for further analysis, and are described below.

Factor 1 - Mindfulness: This factor contains items that constitute a conscious or mindful awareness of one's own thoughts and actions. All of the items are negatively formulated, and thus aim to identify a state of mindless or automatic behaviour. Item 25 ('Often I don't notice what I am doing until someone calls it to my attention') serves as a good example of the items included in this factor. The mindfulnessfactor consists of seven items $(\alpha=.80)$.

Factor 2 - Self-efficacy: This factor contains items that constitute the belief in one's ability to act in a rational, resourceful and goal-directed manner. All of the items are positively formulated, and item 30 ('I can usually find several different possibilities when I want to change something') is a good example of the content of this factor. The self-efficacyfactor consists of six items $(\alpha=.74)$.

Factor 3 - Monitoring change: This factor contains items that represent the ability to keep track of one's progress toward goal attainment. All of the items are positively formulated, and item 5 ('I set goals for myself and keep track of my progress') exemplifies the items contained in this factor. The monitoring change-factor consists of three items $(\alpha=.68)$.

Factor 4 - Goal focus: This factor contains items that encompass the ability to set goals and stick to them. All but one of the items (item 21, which loaded on the factor in the opposite direction to the other items) are negatively formulated, and therefore related to difficulty in both planning goals and following through on plans. Item 1 ('I have trouble making plans to help me reach my goals') serves as a good example of the items included in this factor. The goal focus-factor consists of five items $(\alpha=.63)$.
Factor 7 - Internal locus of control: This factor contains items that constitute living by one's own set of standards and being confident of one's ability to do so. Item 12 ('I have a lot willpower') serves as a good example of the items included in this factor. The internal locus of control-factor consists of three items $(\alpha=.63)$.

\section{Factor structure}

The majority of the extracted factors were thus theoretically interpretable. A total of $47 \%$ of scale variance is explained by these factors, and communalities proved to be in line with what is regarded satisfactory in the social sciences. The result of the exploratory factor analysis can therefore be considered meaningful. In the light of their poor reliability, factors 5, 6 and 8 cannot be considered reliable sub-constructs, yielding Cronbach's alpha values of $0.03,0.22$ and 0.23 respectively. This can partly be explained by the fact that factor 6 and factor 8 contain fewer than three items (Costello \& Osborne, 2005). These factors also contained a number of the items that have in the previous section been indicated as showing problematic psychometric properties. Factors 5, 6 and 8 were therefore not included in the subsequent determination of criterion-related validity. Due to the negative effect it had on the reliability of factor 4, substantially lowering its Cronbach's alpha from .72 to .63 , item 21 was also subsequently omitted from further analysis.

The component correlation matrix of the five reliable factors, along with their respective Cronbach's alpha coefficients, is given in Table 3. These results show that all five of the subconstructs (mindfulness, self-efficacy, monitoring change, goal focus and internal locus of control) that were retained correlate significantly with each other as well as with the total scale score.

\section{Criterion-related validity}

Pearson product moment correlations between the SSRQ total score and its five sub-constructs that were retained for further analysis are provided in Table 4. Criterion-related validity was determined by calculating the correlation

TABLE 3: Cronbach's alpha reliability (in brackets) and component correlation matrix of the Short Self-Regulation Questionnaire.

\begin{tabular}{lllll}
\hline SSRQ-subconstructs & $\mathbf{1}$ & $\mathbf{2}$ & $\mathbf{3}$ & $\mathbf{4}$ \\
\hline 1. Mindfulness & $(.80)$ & - & - & - \\
2. Self-efficacy & $.365^{* *}$ & $(.74)$ & - & - \\
3. Monitoring change & $.308^{* *}$ & $.374^{* *}$ & $(.68)$ & - \\
4. Goal-focus & $.538^{* *}$ & $.186^{* *}$ & $.309^{* *}$ & - \\
5. Internal locus of control & $.320^{* *}$ & $.451^{* *}$ & $.341^{* *}$ & $(.72)$ \\
\hline Total & $.806^{* *}$ & $.680^{* *}$ & $.266^{* *}$ & $(.63)$ \\
\hline
\end{tabular}

**, Correlation is significant at the .01 level (2-tailed).

TABLE 4: Criterion-related validity: Pearson correlation coefficients of the SSRQ components with other measures of psychological well-being (GHQ and MHC-SF) and self-regulation (SRS).

\begin{tabular}{|c|c|c|c|c|c|c|}
\hline Criterion-related validity & Mindfulness & Self-efficacy & Monitoring change & Goal-focus & Internal locus of control & SSRQ total \\
\hline GHQ & $-.203^{* *}$ & -.104 & -.132 & $-.323^{* *}$ & $-.226 * *$ & $-.298 * *$ \\
\hline MHC-SF & $.148^{*}$ & $.344^{* *}$ & $.289 * *$ & $.173^{*}$ & $.216^{* *}$ & $.343 * *$ \\
\hline SRS & $.174^{*}$ & $.252^{* *}$ & $.235 * *$ & $.192^{* *}$ & $.250 * *$ & $.288 * *$ \\
\hline
\end{tabular}

SSRQ, Short Self-Regulation Questionnaire; GHQ, General Health Questionnaire; MHC-SF, Mental Health Continuum - Short Form; SRS, Self Regulation Scale.

$*$, Correlation is significant at the .05 level (2-tailed); ${ }^{*}$, Correlation is significant at the .01 level (2-tailed) 
between these factors and another measure of self-regulation, the SRS, as well as two measures of psychological well-being, the GHQ and the MHC-SF. The SSRQ total score and that of its sub-constructs showed statistically significant correlations with the SRS, with all but one sub-construct correlating at the $10 \%$ level of significance. The SSRQ total score as well as its sub-constructs showed statistically significant positive correlations with participants' well-being, as measured with the MHC-SF. As expected, the SSRQ and all but two of its subscales (i.e. self-efficacy and monitoring change) also correlated negatively with the symptoms of psychopathology as measured with the GHQ.

\section{Discussion}

As the aim of this study was the exploration of the psychometric properties of the SSRQ within a group of Black African teachers; aspects that received attention as proposed by Paunonen and Ashton (1998) included the scale's reliability, criterion-related validity and internal factor structure.

\section{Outline of results}

\section{Descriptive statistics}

Although the overall homogeneity and reliability indices of the SSRQ total scale score proved satisfactory, the Cronbach's coefficient alpha of certain of its sub-constructs were low. This warrants scrutiny of the scale's psychometric properties at the item level. In contrast to item 22, which produced the lowest mean score of 2.48, items 18, 21, 23, 27 and 29 showed the highest means (greater than 4), the lowest standard deviations (.73 to .80$)$, and the largest deviation from normality when considering values for skewness (-.91 to -1.52) and kurtosis (1.35 to 4.29). This signifies that most respondents acquiesced with these items, leading to a lower degree of variation in response as compared to other items. A possible explanation could be that the way in which these items were formulated led participants to respond in a way that they deemed socially desirable. Working in an environment where a lot of value is placed on certain attributes, participants may have found it difficult to disagree with statements like, 'If I wanted to change, I am confident that I could do it' (item 18 ), and 'I can stick to a plan when it is working well' (item 29). Traditionally, Black South African people are more collectivist in cultural orientation, which implies a primary orientation toward group and collective norms, as opposed to an emphasis on the self and individual values as in a Western individualistic orientation (Wissing et al., 2006). However, working in an urbanised environment, this participant group would not only be cognisant of Western individualistic value systems, but have likely adopted these values as their own. It may therefore be that participants viewed responding in the negative to the abovementioned items, which pertain to more individualistic values such as autonomy, independence, and a focus on the future (Wissing et al., 2006), as socially unacceptable in their current work context. This possibility is substantiated by previous findings that individuals with an interdependent sense of self, as would usually be associated with a collectivistic cultural association, are more sensitive to question context (Haberstroh, Oyserman, Schwarz, Kühnen \& Ji, 2002) when responding to self-report questionnaires, and would therefore be more prone to respond in a manner that they deem socially appropriate.

With regard to item total correlations, items 18, 22 and 28 fell below the desirable range. This indicates that the content of these items was not as reliably related to the construct of self-regulation as measured with the SSRQ as the other items. In addition, the value of the Cronbach's alpha for the total scale did not improve with the addition of item 28 , indicating that this item did not contribute to the reliability of the scale. In addition to item 18, which has already been pointed out as a problematic, consideration should be given to the reformulation or omission of items 22 (which also had the lowest mean) and 28 in order to be better aligned with the construct assessed by the overall scale.

\section{Construct validity}

Exploratory factor analysis showed sufficient communalities and yielded the eight factors previously reported: (1) mindfulness, (2) self-efficacy, (3) monitoring change, (4) goal focus, (5) resilience, (6) ability to change, (7) internal locus of control and (8) taking action. Factors 5, 6 and 8 were however found to be unreliable sub-constructs as they yielded poor Cronbach's alpha values, and factors 6 and 8 contained fewer than three items each (Costello \& Osborne, 2005). These factors were therefore not included in the determination of criterion-related validity. Individual items contained in these factors included items 22, 23, 4 (factor 5), 28, 18 (factor 6), 15 and 3 (factor 8). As discussed earlier, the majority of these items (specifically 22, 23, 28 and 18) have already been identified as items that need to be reviewed for future versions of this scale. Addition of items with related content can be considered in future research in order to strengthen the two factors containing fewer than three items, which may lead to improved scale characteristics (Van der Walt, Potgieter, Wissing \& Temane, 2008).

The following factors, which showed sufficient reliability and contained three or more items per factor, were included in the determination of criterion-related validity: (1) mindfulness, (2) self-efficacy, (3) monitoring change, (4) goal focus and (7) internal locus of control. Not only was the item content of the individual sub-constructs readily interpretable, but the composition of sub-constructs was also found to reflect existing self-regulation theory. Specifically, mindfulness (Brown, Ryan \& Creswell, 2007; Langer, 2005), self-efficacy (Luszczynska, Gutiérrez-Doňa \& Schwarzer, 2005; Maddux, 2009), self-monitoring (Carver, 2004; Watson \& Tharp, 2007), goals (Baumgardner \& Crothers, 2010; Maes \& Karoly, 2005) and internal locus of control (Baumeister, Vohs \& Tice, 2007; Ryan \& Deci, 2000) are known to form part of successful self-regulation (Botha, 2013). The significant correlations that were found between these sub-constructs and the total scale score further attest to their reliability. In light of the amount of variance explained, and the satisfactory nature 
of communalities that were found, the results of the factor analysis thus proved to be meaningful.

\section{Criterion-related validity}

In terms of the five factors retained in further analysis, the SSRQ displayed sound criterion-related validity as a measure of self-regulation through its significant correlation with the SRS. A large body of research has shown a link between selfregulation and both the maintenance of psychological wellbeing (Skowron et al., 2003; Sokol \& Müller, 2007) and the development of mental illness (Siegel, 2007). The significant correlations that were found between the SSRQ and the selfreported psychological well-being and psychopathology of Black African participants thus further substantiated its usefulness within this context. This reflects research findings in other contexts (Siegel, 2007; Skowron et al., 2003; Sokol \& Müller, 2007), linking self-regulation to both the maintenance of psychological well-being and the prevention of the development of disorders.

When comparing our results with those found within American student populations (Carey et al., 2004; Neal \& Carey, 2005), a number of interesting divergences came to the fore. In contrast to the seven factors originally proposed by Miller and Brown (1991), and the one-factor and twofactor solutions by Carey et al. (2004) and Neal and Carey (2005) respectively, exploratory factor analysis yielded five interpretable factors with robust factor structure. These differences may be partly due to the fact that the original SRQ was based on a logically derived conceptualisation of the seven dimensions deemed necessary for effective selfregulation by Brown et al. (1999). When the item content of the seven theoretical dimensions of the SRQ was compared with that of the five-factor result yielded by the SSRQ in the current study, however, they proved to represent different constructs. More specifically, where the SRQ's dimensions represent seven more or less sequential steps or phases within the self-regulation process, the five factors found in this study rather represent essential components or skills involved in successful self-regulation. It seems therefore that the degree to which a person possesses these skills will predict successful self-regulation, even if they do not occur in process form or as chronological steps in the self-regulatory process itself.

\section{Limitations and recommendations}

A number of limitations regarding both the study and the measure under scrutiny may have had an effect on the results, creating a need for further research aimed at the refinement of the SSRQ. Firstly, the relatively small number of participants included in this study limited the statistical power of the analysis, as well as the generalisability of results. Future studies should seek to replicate the current methodology in larger, more representative samples. With regard to the scale, exploratory factor analysis yielded a number of factors with fewer than the required minimum of three items. Review of item content and addition of items focused on the indicated factors could improve the overall validity of the scale. A further concern is that questionnaires were completed in English, which was for all participants a second language. Although they indicated their fluency in English, the possibility exists that subtle variations in participants' understanding of item content could have influenced results. Further scrutiny of the length and especially the language used in some of the problematic items could result in improvements in the scale's cross-cultural applicability.

The use of structural equation modeling or item response theory could serve to strengthen results or further validation of the SSRQ. Future studies should ideally include data across different demographic and cultural groups as an attempt to determine whether the results and suggested unique factor groupings in this study can be generalised to other cultural groups in South Africa.

\section{Conclusion}

A large body of research has linked self-regulation with the promotion and maintenance of psychological well-being (Siegel, 2007; Skowron et al., 2003; Sokol \& Müller, 2007). Its potential impact within the challenging South African teaching context can therefore not be neglected (Møller, 2007). As is the case with research on psychological wellbeing in general (Khumalo, Wissing \& Temane, 2008), most of our knowledge on self-regulation emanates from a Western context, which is often characterised as adhering to an individualistic world view. Cultural and contextual factors are known to directly impact both the construction and experience of psychological well-being (Temane \& Wissing, 2008; Wissing \& Temane, 2008; Wissing et al., 2006). Self-regulation scales developed in a Eurocentric context may therefore not be valid in the African context. In his review of South African literature, Botha (2013) reported a lack of dedicated research on self-regulation as preventive strength within this challenging context, which can at least partly be ascribed to a lack of validated psychometric tests to accurately capture this phenomenon.

The current study contributed in this regard by showing that, although individual items need further adjustment and refinement in order to improve the psychometric properties of the scale and strengthen the factor structure of future versions, the overall reliability of the SSRQ within this group of Black African teachers was satisfactory. Focus groups with participants from a similar background and cultural orientation to the participants who partook in this study may serve to enhance the cultural grounding of our findings. The five robust factors that were retained after factor analysis do however provide an indication of the sub-constructs that play an important role in the self-regulation of this group of Black African teachers, and could serve as the basis for the development and evaluation of a more emic instrument for recording self-regulation data within the broader African context. 


\section{Acknowledgements Competing interest}

The authors declare that they have no financial or personal relationship(s) that may have inappropriately influenced them in writing this article.

\section{Authors' contributions}

M.V. (North-West University), J.P. (North-West University), M.T. (North-West University), S.E. (North-West University) and T.K. (North-West University) contributed equally to the writing of this article.

\section{References}

Allard, N.C. (2007). Day surgery for breast cancer: Effects of a psychoeducational telephone intervention on functional status and emotional distress. Oncology Nursing Forum, 34(1), 133-141. http://dx.doi.org/10.1188/07.ONF.133-141, PMid:17562640

Aspinwall, L.G. (2004). Dealing with adversity: Self-regulation, coping, adaptation, and health. In M.A. Malden (Ed.), Applied Social Psychology (pp. 3-27). New York, NY: Blackwell Publishing. http://dx.doi.org/10.1037/0033-2909.121.3.417 PMid:9136643

Aspinwall, L.G., \& Taylor, S.E. (1997). A stitch in time: Self-regulation and proactive coping. Psychological Bulletin, 121, 417-436.

Baumann, N., Kaschel, R., \& Kuhl, J. (2005). Striving for unwanted goals: Stressdependent discrepancies between explicit and implicit achievement motives reduce subjective well-being and increase psychosomatic symptoms Journal of Personality and Social Psychology, 89(5), 781-799. http://dx.doi. org/10.1037/0022-3514.89.5.781, PMid:16351368

Baumeister, R.F., \& Vohs, K.D. (2007). Self-regulation, ego depletion, and motivation. Social and Personality Psychology Compass, 1(10), 1-14

Baumeister, R.F., Vohs, K.D., \& Tice, D.M. (2007). The strength model of self-control. Current Directions in Psychological Science, 16(6), 351-355. http://dx.doi. org/10.1111/j.1467-8721.2007.00534.x

Baumgardner, S.R., \& Crothers, M.K. (2010). Positive Psychology. Upper Saddle River, NJ: Pearson.

Beckmann, J., \& Kellmann, M. (2004). Self-regulation and recovery: Approaching an understanding of the process of recovery from stress. Psychological Reports, 95, 1135-1153. http://dx.doi.org/10.2466/PR0.95.7.1135-1153, http://dx.doi. org/10.2466/pr0.95.3f.1135-1153, PMid:15762394

Botha, K. (2013). Self-regulation as psychological strength in South Africa: A review. In M.P. Wissing (Ed.), Well-being Research in South Africa. Düsseldorf, Germany: Springer Verlag. http://dx.doi.org/10.1007/978-94-007-6368-5_23

Brown, J.M., Miller, W.R., \& Lawendowski, L.A. (1999). The self-regulation questionnaire. In L. VandeCreek, \& T.L. Jackson (Eds.), Innovations in clinical practice: A sourcebook (pp. 281-292). Sarasota, FL: Professional Resource Press/ Professional Resource Exchange.

Brown, K.W., Ryan, R.M., \& Creswell, J.D. (2007). Mindfulness: Theoretical foundations and evidence for its salutary effects. Psychological Inquiry, 18(4), 211-237. http:// dx.doi.org/10.1080/10478400701598298

Caprara, G.V., \& Steca, P. (2006). The contribution of self-regulatory efficacy beliefs in managing affect and family relationships to positive thinking and hedonic balance. Journal of Social and Clinical Psychology, 25(6), 603-627. http://dx.doi. org/10.1521/jscp.2006.25.6.603

Carey, K.B., Neal, D.J., \& Collins, S.E. (2004). A psychometric analysis of the selfregulation questionnaire. Addictive Behaviors, 29, 253-260. http://dx.doi. org/10.1016/j.addbeh.2003.08.001, PMid:14732414

Carver, C.S. (2004) Self-regulation of action and affect. In R.F. Baumeister, \& K.D. Vohs (Eds.), Handbook of Self-Regulation. Research, Theory, and Applications. London, UK: Guilford Press.

Clark, L.A., \& Watson, D. (1995). Constructing validity: Basic issues in objective scale development. Psychological Assessment, 7(3), 309-319. http://dx.doi. org/10.1037/1040-3590.7.3.309

Coetzee, M., Jansen, C., \& Muller, H. (2008). Stress, coping resources and personality types: An exploratory study of teachers. Acta Academia, 41(3), 168-200. Available

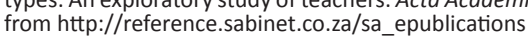

Costello, A.B., \& Osborne, J.W. (2005). Best practices in exploratory factor analysis: Four recommendations for getting the most from your analysis. Practical Assessment Research and Evaluation, 10(7), 1-9.

Ferreira, R. (2008). Culture at the heart of coping with HIV/AIDS. Journal of Psychology in Africa, 18(1), 97-104.

Field, A. (2013). Discovering statistics using IBM SPSS Statistics. London, UK: SAGE Publications.
Forgas, J.P., Baumeister, R.F., \& Tice, D.M. (2009). The psychology of self-regulation. An introductory review. In J.P. Forgas, R.F. Baumeister, \& D.M Tice (Eds.), Psychology of Self-Regulation. Cognitive, Affective, and Motivational Processes (pp. 1-20). of Self-Regulation. Cognitive, Affed
New York, NY: Psychology Press.

Goldberg, D.P., \& Hillier, V.F. (1979). A scaled version of the General Health Questionnaire. Psychological Medicine, 9, 139-145. http://dx.doi.org/10.1017/ Questionnaire. Psychological Medicinat
S0033291700021644, PMid:424481

Gramzow, R.H., Sedikides, C., Panter, A.T., \& Insko, C.A. (2000). Aspects of selfregulation and self-structure as predictors of perceived emotional distress. Personality and Social Psychology Bulletin, 26, 188-205. http://dx.doi. org/10.1177/0146167200264006

Haberstroh, S., Oyserman, D., Schwarz, N., Kühnen, U., \& Ji, L. (2002). Is the interdependent self more sensitive to question context than the independent self? Self-construal and the observation of conversational norms. Journal of Experimental Social Psychology, 38, 323-329. http://dx.doi.org/10.1006/ jesp.2001.1513

Hair, J.F., Anderson, R.E., Tatham, R.L., \& Black, W.C. (2005). Multivariate data analysis. (6th edn.). Englewood Cliffs, NJ: Prentice Hall.

Howitt, D., \& Cramer, D. (2008). Introduction to SPSS in Psychology. (4th edn.). Harlow, UK: Pearson Education Ltd.

Ibaňez, M.I., Ruipérez, M.A., Moya, J., Marqués, M.J., \& Ortet, G. (2005). A short version of the self-regulation inventory (SRI-S). Personality and Individual Differences, 39, 1055-1059. http://dx.doi.org/10.1016/j.paid.2005.02.029

Jackson, L., \& Rothmann, S. (2005). Work-related well-being of educators in a district of the North-West Province. Perspectives in Education, 23(3), 107-122. Available

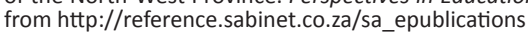

Keyes, C.L.M. (2005). The subjective well-being of America's youth: Toward a comprehensive assessment. Adolescent and Family Health, 4, 3-11.

Keyes, C.L.M., Wissing, M., Potgieter, J.P., Temane, Q.M., Kruger, A., \& Van Rooy, S. (2008). Evaluation of the Mental Health Continuum-Short Form (MHC-SF) in Setswana-speaking South Africans. Clinical Psychology and Psychotherapy, 15, 181-192. http://dx.doi.org/10.1002/cpp.572, PMid:19115439

Khan, A. (2012). Teacher's stress, performance \& resources: The moderating effects of resources on stress \& performance. International Review of Social Sciences and Humanities, 2(2), 21-29.

Khumalo, I.P., Wissing, M.P. \& Temane, Q.M. (2008). Exploring the validity of the values-in-action inventory of strengths (VIA-IS) in an African context. Journal of values-in-action inventory of strength
Psychology in Africa, 18(1), 133-142.

Langer, E. (2005). On becoming an artist. Reinventing yourself through mindful creativity. New York, NY: Ballantine Books.

Lund, C., Flisher, A.J. (2006). Norms for mental health services in South Africa. Social Psychiatry \& Psychiatric Epidemiology, 41, 587-594. http://dx.doi.org/10.1007/ s00127-006-0057-z

Luszczynska, A., Gutiérrez-Doňa B., \& Schwarzer R. (2005). General selfefficacy in various domains of human functioning: Evidence from five countries. International Journal of Psychology, 40(2), 80-89. http://dx.doi. org $/ 10.1080 / 00207590444000041$

Maddux, J.E. (2009). Self-efficacy. The power of believing you can. In C.R. Snyder, \& S.J. Lopez. (Eds.), Oxford Handbook of Positive Psychology. (2nd edn.). New York, NY: Oxford University Press. http://dx.doi.org/10.1093/ oxfordhb/9780195187243.013.0031, PMCid:PMC2807975

Maes, S., \& Karoly, P. (2005). Self-regulation and intervention in physical health and illness: A review. Applied Psychology: An International Review, 54(2), 267-299. http://dx.doi.org/10.1111/j.1464-0597.2005.00210.x

Mashele, N., Van Rooyen, J.M., Malan, L., \& Potgieter, J.C. (2010). Cardiovascular function and psychological distress in urbanised black South Africans: The SABPA study. Cardiovascular Journal of Africa, 21(4), 206-211. PMid:20838719

Miller, W.R., \& Brown, J.M. (1991). Self-regulation as a conceptual basis for the prevention and treatment of addictive behaviours. In N. Heather, W.R. Miller, \& J. Greely (Eds.), Self-control and the addictive behaviours (pp. 3-79). Sydney, Australia: Maxwell Macmillan.

Møller, V. (2007). Quality of life in South Africa - The first ten years of democracy Social Indicators Research, 81(2), 181-202. http://dx.doi.org/10.1007/s11205006-9003-4

Neal, D., \& Carey, K. (2005). A follow-up psychometric analysis of the self-regulation questionnaire. Psychology of Addictive Behaviors, 19(4), 414-422. http://dx.doi. org/10.1037/0893-164X.19.4.414, PMid:16366813

Nunnally, J.C., \& Bernstein, I.H. (1994). Psychometric theory. (3rd edn.). New York, NY: McGraw-Hill.

Parker, P.D., Martin, A.J., Colmar, S., \& Liem, G.A. (2012). Teachers' workplace well-being: Exploring a process model of goal orientation, coping behavior,
engagement, and burnout. Teaching and Teacher Education, 28, 503-513. http:// engagement, and burnout. Teaching and

Paunonen, S.V., \& Ashton, M.C. (1998). The structured assessment of personality across cultures. Journal of Cross-cultural Psychology, 29(1), 150-170. http:// dx.doi.org/10.1177/0022022198291008

Potgieter, J.C., \& Botha, K.F.H. (2009). Psychometric properties of the short selfregulation questionnaire (SSRQ) in a South African context. Journal of Psychology in Africa, 19(3), 321-328.

Ryan, R.M., \& Deci, E.L. (2000). Self-determination theory and the facilitation of intrinsic motivation, social development, and well-being. American Psychologist, 55(1), 68-78. http://dx.doi.org/10.1037/0003-066X.55.1.68 
Saraceno, B. (1998). Nations for mental health: A new WHO action programme on mental health for underserved populations. European Psychiatry, 13(4), 164. http://dx.doi.org/10.1016/S0924-9338(99)80120-5

Schwarzer, R., Diehl, M., \& Schmitz, G.S. (1999). Self-Regulation Scale. Retrieved October 28, 2006, from http://www.fu-berlin.de/gesund/skalen

Siegel, D.J. (2007). Mind your brain. New York, NY: W.W. Norton \& Company

Skowron, E.A., Holmes, S.E. \& Sabatelli, R.M. (2003). Deconstructing differentiation: Selfregulation, interdependent relating and well-being in adulthood. Contemporar Family Therapy, 25(1), 111-129. http://dx.doi.org/10.1023/A:1022514306491

Sokol, B.W., \& Müller, U. (2007). The development of self-regulation: Toward the integration of cognition and emotion. Cognitive Development, 22(4), 401-405. $\mathrm{http}: / / \mathrm{dx}$.doi.org/10.1016/j.cogdev.2007.08.008

Temane, Q.M., \& Wissing, M.P. (2008). The role of personality factors in the dynamics of context and psychological well-being. Journal of Psychology in Africa, 18(1), 105-114.

Van der Walt, D., Potgieter, J.C., Wissing, M.P., \& Temane, Q.M. (2008). Validation of coping scale in an African context. Journal of Psychology in Africa, 18(1), 155-166.
Watson, D.L., \& Tharp, R.G. (2007). The principles of self-regulation: Theory and practice. In D.L. Watson, \& R.G. Tharp (Eds.), Self-directed behaviour. Selfmodification for personal adjustment. Belmot, CA: Thomson Wadsworth.

Wissing, M.P., \& Temane, Q.M. (2008). The structure of psychological well-being in cultural context: Towards a hierarchical model of psychological health. Journal of Psychology in Africa, 18(1), 45-56.

Wissing, M.P., \& Van Eeden, C. (2002). Empirical clarification of the nature of psychological well-being. South African Journal of Psychology, 32(1), 32-44.

Wissing, M.P., Wissing, J.A.B., Du Toit, M.M., \& Temane, Q.M. (2006). Patterns of psychological well-being and satisfaction with life in a cultural context. In A. Delle Fave (Ed.), Dimensions of well-being: Research and intervention (pp. 14-33). Milano, Italy: Franco Angeli.

World Health Organisation (2004). Prevention of mental disorders: Effective interventions and policy options. Retrieved October 18, 2013, from http://www. who.int/mental_health/evidence/en/prevention_of_mental_disorders_sr.pdf

World Health Organisation (2013). NCD global monitoring framework: Ensuring progress on NCD's in countries. Retrieved February 27, 2013, from http://www. who.int/nmh/en/ 